\title{
SACOLAS PLÁSTICAS: UMA QUESTÃO DE MUDANÇA DE HÁBITOS
}

\author{
PLASTIC BAGS: AQUESTION OF CHANGING HABITS \\ Juliana Benitti Lorenzett ${ }^{1}$; Cláudia Bach Rizzatti ${ }^{2}$; Daniel Benitti Lorenzett ${ }^{3}$; \\ Leoni Pentiado Godoy ${ }^{4}$ \\ ${ }^{1}$ Instituto Estadual de Educação Vicente Dutra (IEEVD) \\ ${ }^{2,3,4}$ Programa de Pós-Graduação em Engenharia de Produção (UFSM), \\ dlorenzett@gmail.com
}

http://dx.doi.org/10.5902/223613087725

\section{RESUMO}

Este trabalho objetivou a realização de uma revisão sobre o uso e descarte de sacolas plásticas, verificando na literatura existente o que vem sendo estudado e a situação atual dessa problemática ambiental, além da realização de um levantamento com os clientes de um supermercado para verificar o comprometimento da comunidade com a adoção de sacolas retornáveis. A pesquisa bibliográfica foi realizada pela internet, sendo considerados, portanto, trabalhos disponíveis online. O estudo de levantamento se deu com os clientes de um supermercado na cidade de Santa Maria, RS. Os resultados demonstraram que o interesse em pesquisas na área é recente, e que ainda existe um longo caminho para se chegar a um consenso sobre o uso e descarte das sacolas plásticas. $O$ trabalho de levantamento apontou que as pessoas estão cientes da importância da substituição das sacolas plásticas tradicionais, entretanto, apesar de dispostas a mudar, a maioria delas ainda não aderiu ao uso de embalagens alternativas.

Palavras-chave: sacolas plásticas descartáveis; poluição; sacolas retornáveis.

\begin{abstract}
This study aimed to conduct a review about of the use and disposal of plastic bags, checking in the existing literature that has been studied and the current status of this environmental problem, besides conducting a survey with customers in a supermarket to check the involvement of the community with the adoption of reusable bags. A bibliographic search was conducted by internet, and is considered therefore works available online. The study survey was given to the customers of a supermarket in the city of Santa Maria, RS. The results showed that the interest in researching this topic is recent, and there is still a long way to achieve at a consensus on the use and disposal of plastic bags. The survey work showed also that people are aware of the importance of replacing the traditional plastic bags, however, the most of them have not yet acceded to the use of alternative packaging.
\end{abstract}

Keywords: disposable plastic bags; pollution; reusable bags. 


\section{INTRODUÇÃO}

Atualmente, muitos são os problemas de ordem ambiental que causam degradação dos ecossistemas, da água, dos solos, da fauna e da flora. O assoreamento de rios, córregos e nascentes, a contaminação de mananciais com efluentes líquidos, a erosão do solo, o desmatamento, as queimadas, o tráfico de animais ameaçados de extinção, a caça e a pesca predatória e ilegal, os agrotóxicos utilizados na agricultura, todos estes são problemas ambientais atuais e recorrentes que prejudicam diretamente a qualidade e o equilíbrio ambiental.

Outro problema ambiental atual consiste no uso e descarte inadequado das sacolas plásticas distribuídas nos supermercados. Proibidas em muitos países, elas representam cerca de 4 milhões de kg de plástico lançados anualmente nos mares. O impacto causado pelo descarte inadequado do saco plástico atinge os mais diversos lugares, resultando em poluição visual e até a morte de diversos animais.

Comumente descartadas na natureza, as sacolas plásticas são carregadas pelos ventos e pelas águas por longas distâncias e acabam se concentrando principalmente nos oceanos, onde poluem as águas e causam sérios prejuízos à vida marinha. Nos oceanos, as principais vítimas são as baleias, os golfinhos, as focas, as tartarugas e as aves marinhas, que morrem ao ficarem presas nesses materiais ou mesmo por ingeri-los ao confundi-los com comida (GUIMARÃES e ALBUQUERQUE, 2010). Estima-se que mais de cem mil mamíferos e pássaros morram por ano devido à ingestão de sacos plásticos (SILVA, 2012).

As sacolas plásticas demoram a se decompor e acabam por formar grandes montes de lixo nos oceanos. Quando elas se decompõem, transformam-se em petro-polímeros, que são substâncias altamente tóxicas, contaminando as águas e o solo. Países como Tanzânia, Bangladesh, China, Israel, Canadá, Índia, Quênia, Irlanda, África do Sul, Uganda, Butão, Taiwan, Maharashtra, Botswana, Singapura, Ruanda e Eritréia, já proibiram o uso de sacolas plásticas (PÓVOA NETO et al., 2011). Fato esse que contribui significativamente para prevenção da poluição ambiental, principalmente das águas e dos oceanos, pois a grande maioria dos sacos plásticos, descartados no lixo doméstico, acaba indo parar nos oceanos, aliás, o homem tem feito dos oceanos uma grande lixeira permanente onde são descartados os mais diversos tipos de rejeitos da humanidade.

O uso de plásticos pela sociedade contemporânea está cada vez mais acentuado, e esse uso demasiado em excesso tem trazido sérios problemas ambientais ao mundo moderno (PÓVOA NETO et al., 2011). Assim, torna-se necessário incentivar a redução do uso de sacos plásticos, pois uma única pessoa, no Brasil, consome em média aproximadamente 790 sacos plásticos por ano. Nesse sentido, cada um pode fazer a diferença a fim de melhorar a qualidade ambiental.

Atualmente, as sacolas plásticas representam 10\% de todo lixo produzido no Brasil, e cada brasileiro utiliza 19 quilos de sacolas por ano (OLIVEIRA et al., 2012). No país, a iniciativa para abolir as sacolas plásticas dos supermercados partiu do estado de São Paulo, mas não tem dado muito certo. A proibição data do inicio do ano de 2012, mas em junho do mesmo ano, as sacolas voltaram a ser distribuídas, pois os supermercados acabaram transformando uma medida protetiva do meio ambiente em uma forma de lucrar na venda de sacos de lixo e outras formas de embalagem. Recentemente, em 2013 o Tribunal de Justiça do Estado de São Paulo derrubou a liminar que garantia a distribuição gratuita de sacolas plásticas, que passam a ser vendidas novamente pelos supermercados a partir de abril de 2013.

Este trabalho tem por objetivo realizar uma revisão sobre a problemática do uso e descarte das sacolas plásticas, verificando na literatura existente as pesquisas realizadas sobre esse tema, 
na tentativa de identificar meios alternativos ao uso e descarte adequado desses materiais, tão agressivos ao meio ambiente. Para tanto, realizar-se-á, também, um levantamento com alguns clientes de um supermercado localizado na cidade de Santa Maria (RS) para verificar seu grau de comprometimento com a utilização de sacolas retornáveis.

\section{ENTENDENDO A DINÂMICA DAS SACOLAS PLÁSTICAS}

Atualmente, o plástico encontra-se em quase tudo o que é produzido pelo homem, desde a cadeira até o automóvel, seja no computador ou protegendo e mantendo os alimentos limpos e frescos, o plástico está presente no dia-a-dia de toda a população. Ele chegou a pouco mais de 50 anos, mas se tornou tão usual e fundamental, nas mais diversas situações, que parece difícil pensar a humanidade vivendo sem sua presença. Mais difícil que pensar na humanidade sem o plástico seria viver isso na prática, pois apesar de tão pouco tempo usando-o, nesses últimos anos o descarte irregular do plástico acabou poluindo boa parte dos rios, lagos, vales, mares e do solo nas mais diversas partes do globo terrestre, fato que faz o ser humano repensar o custo $x$ benefício desta prática (PORTAL EDUCAÇÃO, 2012).

As sacolas plásticas demoram cerca de 200 anos para se decompor quando estão soterradas no lixo, e quando ficam expostas a radiação solar, geralmente se decompõem em um ano (ZIEGLER, 2010). Assim, a demora na deterioração deste material não é o maior de todos os problemas ambientais causados por ele. O grande problema centra-se no processo de fabricação das sacolas de polietileno, uma vez que este material, derivado do petróleo, é altamente poluente, nocivo à fauna e a flora.

Atualmente, muito se discute sobre o uso correto das sacolas plásticas. Em alguns estados brasileiros, já é Lei o uso das sacolas "oxi-biodegradáveis". Muitos supermercados aderiram ao uso de sacolas de plástico oxi-degradável, adotando-as como forma alternativa ao uso de sacolas plásticas descartáveis. Estas sacolas recebem um aditivo no momento da produção que acelera sua degradação. Assim, a sacola deve se decompor em no máximo 18 meses (ZIEGLER, 2010; PORTAL EDUCAÇÃO, 2012). Entretanto, o problema não é somente o tempo que este material demora em se decompor, mas sim, a maneira como ele é descartado, pois as substâncias resultantes de sua decomposição também são altamente poluentes.

Seguindo uma tendência visível nos países africanos, como Ruanda, por exemplo, que já proibiu o uso de sacolas plásticas, para proteger o meio ambiente e preservar sua fauna, recentemente o governo da Mauritânia decidiu proibir o uso de sacolas plásticas no país. Conforme a BBC (2012), mais de $70 \%$ dos bois e ovelhas localizados na capital do país, Nouakchott, morreram após ingerir sacolas plásticas. Segundo a BBC com a proibição quem fabricar o produto no país poderá ser preso por até um ano. Conforme estatísticas do governo da Mauritânia, o plástico corresponde a $25 \%$ de todo o lixo produzido na capital do país. Segundo o ministro do Meio Ambiente do país, Amedi Camara, as sacolas plásticas não são coletadas e não recebem tratamento adequado, permanecendo no meio ambiente, onde causam danos principalmente a fauna (BBC, 2013).

Conforme a campanha "Saco é um saco" do Ministério do Meio Ambiente (2013), cada pessoa no Brasil consome em média 66 sacolas plásticas por mês, e estima-se que o mundo consuma até um trilhão dessas sacolas por ano. No Brasil, os supermercados distribuem cerca de 1 bilhão de sacos plásticos por mês, e no mundo são consumidos cerca de 1 milhão de sacos plásticos por minuto. Assim, este é o resíduo que mais polui as cidades e os campos, prejudicando 
a fauna e a flora, entupindo a drenagem urbana e dos rios, provocando inundações e uma série de outros problemas socioambientais (PORTAL EDUCAÇÃO, 2012).

Independente da fonte de matéria prima (renovável ou não), a utilização de sacolas plásticas gera impactos ambientais. Ainda assim, defende-se o uso de recursos renováveis em sua produção, pois a fixação do carbono para estes recursos ocorre em um prazo substancialmente menor, além do recurso não se esgotar tão rapidamente (ZIEGLER, 2010).

Como alternativa ao uso da sacola plástica descartável emerge a sacola de papel, entretanto a sacola de papel tem mais contras do que prós. A pesar de serem bonitas elas não são resistentes ao peso e a umidade. Sem mencionar que a indústria de celuloso, fonte de matéria prima para o papel, é uma indústria altamente poluidora, pois gera muitos resíduos químicos que geralmente são descartados nos rios poluindo as águas superficiais e o solo (ZIEGLER, 2010).

No ano de 2012 a mídia brasileira trouxe à tona uma discussão acerca da substituição das sacolas plásticas nos supermercados, principalmente em função da proibição de seu uso no estado de São Paulo. A medida adotada em algumas cidades no país dividiu a opinião pública, e a questão balizadora da polêmica consiste em até que ponto o não fornecimento de sacolas por redes de supermercado e outros estabelecimentos contribui contra a poluição do meio ambiente? (RIBEIRO, 2013). Assim, se a redução do uso de sacolas plásticas pode contribuir na luta contra a poluição e a degradação ambiental, obviamente, também é válido estender a prática para além delas, pois sem dúvida alguma, as embalagens dos diversos produtos consumidos diariamente pelos seres humanos são poluentes.

Um aspecto central na discussão foi a alternativa apontada para a solução do problema, que consiste na substituição das sacolas tradicionais por sacolas $100 \%$ biodegradáveis. Entretanto, as sacolas, que antes eram oferecidas gratuitamente, agora deveriam ser pagas pelo consumidos. Observa-se, nesse contexto, que por mais que as sacolas sejam recicláveis, elas necessitam de um tratamento específico, caso contrário vão poluir da mesma forma que a sacola convencional, só que desta vez quem paga a conta é o consumidor (RIBEIRO, 2013).

Após uma série de processos a associação civil SOS Consumidor conseguiu, em junho de 2012, uma liminar que obrigava a volta da distribuição de sacolas plásticas gratuitas no estado de São Paulo. Entretanto, em 2013, a 1ạ Vara Cível do Tribunal de Justiça de São Paulo cassou essa liminar, estabelecendo a não gratuidade das sacolas plásticas, que voltarão a ser vendidas pelos supermercados a partir de abril de 2013 por um valor não superior a $\mathrm{R} \$ \mathbf{0 , 5 9}$. A justificativa dessa ação foi que a medida centra-se na proteção e preservação ambiental, não tendo o intuito de gerar lucros aos supermercados com a venda das sacolas, mas sim na redução do seu uso (DEIRO, 2012).

O fator mais importante no momento da escolha por um ou outro meio para carregar as compras, sob o ponto de vista da preservação ambiental, é observar a durabilidade e capacidade de reutilização das sacolas. Nesse contexto, dois tipos de sacolas se destacam, são as sacolas de pano e as ecobags (feitas com polietileno, porém reutilizáveis, mais duráveis e resistentes), pois quanto maior a reutilização das sacolas menor será sua produção e consequentemente menores serão os impactos ambientas (ZIEGLER, 2010; PORTAL EDUCAÇÃO, 2012). Já para os que possuem meio de transporte próprio, uma solução barata e ecologicamente correta para acomodar as compras é o uso de caixas de papelão, que podem ser recicladas após um intenso período de uso (ZIEGLER, 2010). 


\section{METODOLOGIA DA PESQUISA}

O presente trabalho classifica-se como qualitativo, pois procura estudar o problema do uso de sacolas plásticas descartáveis por meio do uso de um levantamento bibliográfico, aliado a um levantamento via questionário para verificar a aceitação da substituição das sacolas descartáveis por sacolas retornáveis. Desse modo, o trabalho pode ser considerado descritivo, tendo a revisão de literatura se processado exclusivamente em material disponibilizado online na internet. Assim, a coleta de dados bibliográficos foi realizada por meio da Plataforma de Periódicos CAPES e por meio do Site de Busca Google.

A pesquisa de levantamento junto à comunidade foi realizada na cidade de Santa Maria, Região Central do Estado do Rio Grande do Sul. Na ocasião, foram entrevistados 150 pessoas, por meio de um questionário com perguntas fechadas. A amostra é não probabilística, representando apenas a situação local, estando focada ao público cliente de um supermercado específico, pioneiro na adoção do uso de sacolas retornáveis na região.

\section{RESULTADOS E DISCUSSÕES}

Nos últimos anos a sociedade em geral despertou para a necessidade de mudança de hábitos relacionados à proteção e preservação do meio ambiente. Nesse contexto, o problema da utilização e descarte inadequado de sacos plásticos tem motivado a realização de diversos tipos de pesquisas recentes sobre o tema.

Por meio de um levantamento junto ao Periódico CAPES e ao site de busca Google foi possível encontrar sete pesquisas, todas recentes, sobre o tema. As publicações ocorreram uma em 2009, duas em 2010, três em 2011 e uma em 2012, o que demonstra quão recente é o interesse no assunto. Das sete pesquisas encontradas três foram publicadas em periódicos, duas em anais de eventos, uma era um trabalho monográfico de conclusão de curso e a outra era um relatório de pesquisa. A seguir são apresentadas as informações mais relevantes sobre as referidas pesquisas.

Póvoa Neto et al. (2011) realizaram um estudo bibliográfico sobre possibilidades de mudança de hábitos como alternativa capaz de minimizar os danos causados ao meio ambiente, colocando a educação ambiental como fator essencial para atingir um nível desejado de responsabilidade socioambiental da população. Em seu estudo, os autores entendem que o maior desafio para a Educação Ambiental é incentivar o consumo consciente, pois a sociedade moderna é uma sociedade consumista. Nesse contexto, a mudança de hábitos relacionada ao uso de sacolas plásticas descartáveis torna-se fundamental para uma sociedade que almeja um futuro mais sustentável. Assim, essa mudança de atitude possui implicações valiosas para a manutenção da qualidade ambiental, pois o elevado volume de sacolas plásticas utilizadas diariamente demonstra a magnitude do impacto negativo acumulado ao longo dos anos.

Queiroz e Garcia (2011) realizaram um estudo com o objetivo de apresentar a influência da taxa média brasileira de reciclagem de sacolas plásticas de polietileno sobre o inventário de ciclo de vida das sacolas plásticas de polietileno no Brasil. Os autores concluíram que a influência da taxa de reciclagem de plástico sobre os parâmetros inventariados é bastante proporcional, sendo que os indicadores de consumo e emissões diminuem à medida que a taxa de reciclagem 
aumenta. Assim, entende-se que a reciclagem ajuda a melhorar o perfil ambiental das sacolas plásticas de Polietileno medido com dados do inventário de ciclo de vida.

Para posicionar a Educação Ambiental como estratégia para mudança de hábito dos consumidores, em favor do consumo consciente e descarte responsável, Villela e Eigenheer (2011) realizaram um estudo junto às comunidades católicas, visando estimular comportamentos ambientalmente responsáveis, principalmente no que diz respeito à substituição das sacolas plásticas fornecidas por supermercados para embalagem e transporte de compras, por sacolas resistentes ao uso prolongado, produzidas com matéria-prima renovável. Como resultado, os pesquisadores observaram que o conhecimento possui uma força positiva na mudança de pensamento e comportamento das pessoas, que degradam porque desconhecem o efeito de suas ações. Assim, a desinformação é o que alimenta o ciclo insustentável, pois sem o estímulo da informação as pessoas continuam a reproduzir práticas ambientalmente incorretas.

Oliveira et al. (2012) estudaram os impactos ambientais causados pelas sacolas plásticas em Campina Grande, PB, para identificar a relação do uso de sacolas plásticas e seus impactos ambientais. Os autores concluíram ao final da pesquisa que a utilização das sacolas plásticas acontece por uma questão cultural e de comodidade, porém a maioria dos usuários é consciente dos impactos ambientais por elas causados. O resultado da pesquisa demonstrou que a maioria do público alvo da pesquisa considera correta a proibição do uso das sacolas plásticas em razão dos impactos ambientais causados, inclusive estando dispostos a utilizar embalagens alternativas como a sacolas retornáveis e caixas de papelão.

Guimarães e Albuquerque (2010) publicaram um estudo que versa sobre a temática do descarte indiscriminado das sacolas plásticas, objetivando trazer ao ambiente acadêmico a discussão e a vivência da Transdisciplinaridade. Segundo os autores, a pesquisa possibilitou uma significativa conscientização dos impactos ambientais causados pelo descarte indiscriminado de plástico no meio ambiente. Buscando, dessa forma, por meio da Educação Ambiental, levar o conhecimento e o debate a diferentes ambientes, possibilitando, assim, espaços de reflexão sobre o tema, que resulta muitas vezes em mudança de hábitos. Santana (2009), em seu estudo, analisou a questão do descarte inadequado dos resíduos de plástico no lixo urbano. Constatou ao final do estudo que a alternativa mais segura e efetiva para reduzir os resíduos de plástico no lixo urbano é por meio da redução na utilização desse material.

Medeiros et al., (2010) estudaram, no município de Volta Redonda no Estado do Rio de Janeiro, os impactos na percepção do consumidor resultantes da substituição de sacolas de polietileno por sacolas alternativas, como apelo ambiental nos supermercados. Os resultados demonstraram que os respondentes entendem os malefícios trazidos pelo uso dos sacos plásticos, entretanto, a grande maioria não concorda com a imposição do não uso de sacolas plásticas nos supermercados, pois as alternativas para embalar as compras muitas vezes não são adequadas. Como os sacos plásticos são reutilizados para embalar o lixo residencial, os clientes entendem que deverão adquirir outras embalagens para embalar esse lixo, assim a mediada seria economia e ambientalmente inviável, pois os sacos plásticos continuariam a poluir o meio ambiente.

Para verificar o grau de envolvimento da comunidade com o problema gerado pelo uso das sacolas descartáveis realizou-se um levantamento com alguns clientes de um supermercado pioneiro no o uso de sacolas retornáveis na cidade de Santa Maria, RS. Foram entrevistados 150 clientes aleatoriamente, sendo que a maioria dos respondentes possuía idade entre 20 e 30 anos, e eram do gênero feminino.

A grande maioria dos entrevistados (54\%), conforme se observa no Gráfico $1 \mathrm{~A}$, entende e aceita a necessidade de substituição das sacolas tradicionais descartáveis pelas sacolas 
retornáveis. A controvérsia situa-se no fato de que apesar de entenderem a necessidade de mudança de hábitos apenas $20 \%$ do total de entrevistados utiliza sacolas retornáveis regularmente (GRÁFICO 1B).
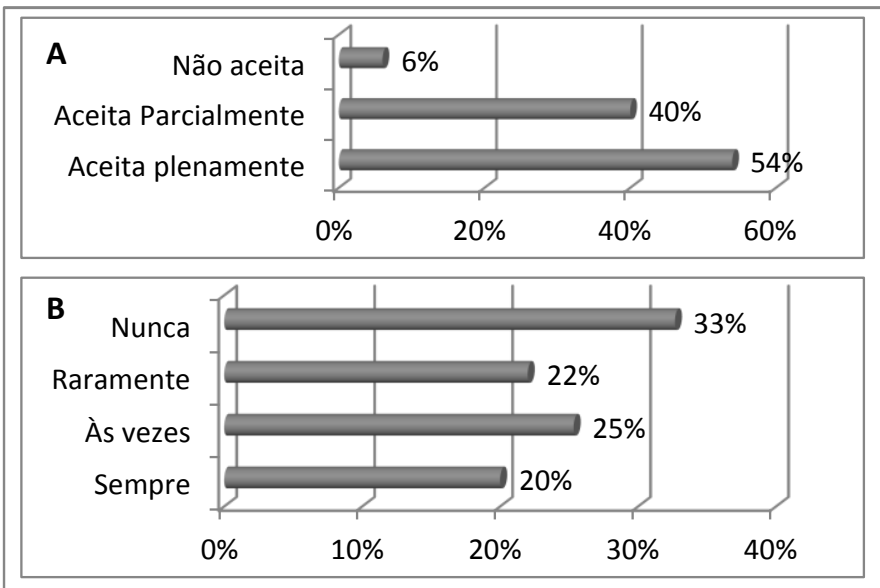

Gráfico 1: Aceitação das sacolas retornáveis (A) e utilização dessas embalagens (B)

Fonte: Levantamento (2012)

Analisando-se a importância atribuída ao uso de sacolas retornáveis, verifica-se conforme Gráfico $2 \mathrm{~A}$, que $57 \%$ dos entrevistados consideram a adoção dessa nova prática muito importante. Observa-se ainda, que essa prática contribui principalmente para uma redução da poluição ambiental causada pela má disposição dos resíduos desses materiais, pois 62\% (GRÁFICO 2B) dos respondentes considera que existe vantagem ambiental na adesão ao uso de sacolas retornáveis.

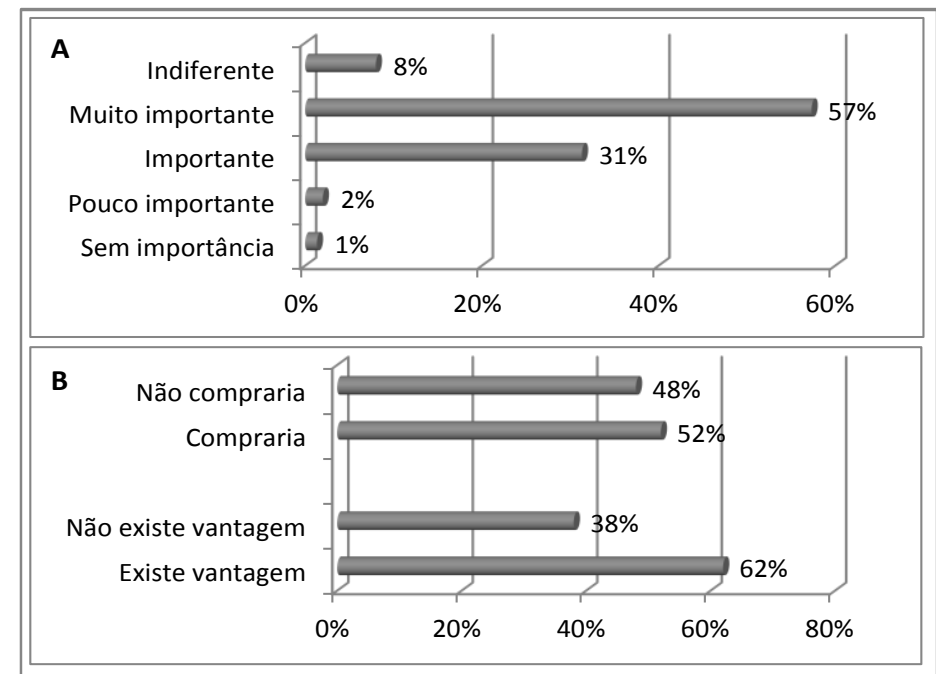

Gráfico 2: Importância do uso das sacolas retornáveis atribuída pelos entrevistados (A), a questão da venda de sacolas retornáveis pelos supermercados e vantagens do uso de sacolas retornáveis ao meio ambiente (B)

Fonte: Levantamento (2012) 
Outra questão importante levantada foi quanto ao custo da adoção de sacolas retornáveis, nesse momento, apesar de a maioria dos respondentes ter respondido que não se importaria em ter que pagar pela sacola retornável, observou-se comparando os dados do Gráfico 2, que pelo menos $10 \%$ dos respondentes apesar de entender as vantagens ambientais do uso de sacolas retornáveis entendem que o ônus com a adesão dessas sacolas não deveria ser repassado ao consumidor.

\section{CONSIDERAÇÕES FINAIS}

Este trabalho realizou uma revisão de literatura sobre o uso e descarte das sacolas plásticas. Por meio da pesquisa de revisão verificou-se que ainda existem poucos trabalhos publicados sobre o tema em estudo, sendo que os trabalhos encontrados são todos trabalhos recentes.

A grande maioria dos trabalhos traz estudos sobre o uso das sacolas plásticas de polietileno e a necessidade de transição para o uso de embalagens sustentáveis, apontando a Educação Ambiental como caminho que leva a conscientização dos malefícios trazidos pela prática do uso diário de sacolas plásticas, considerando que o caminho para a mudança de hábitos está no conhecimento.

Por meio do levantamento com alguns clientes de um supermercado localizado na cidade de Santa Maria, RS, foi possível verificar que essas pessoas estão cientes dos problemas ambientais causados pelo uso e descarte inadequado das embalagens plásticas. A grande maioria dos participantes da pesquisa considera o uso de sacolas retornáveis mais viável e ambientalmente correto, propondo-se inclusive a pagar por esse processo de transição.

Entretanto, apesar dessas pessoas entenderem a gravidade do problema e estarem dispostas a mudarem seus hábitos, notou-se que a grande maioria delas ainda não utiliza as sacolas retornáveis no supermercado. Isso demostra o descaso da população local com a questão, pois a maioria dos entrevistados são poluidores conscientes. Neste caso, em específico, pode-se concluir que o conhecimento não resultou na mudança de hábitos.

\section{REFERENCIAS}

BBC. Mauritânia proíbe uso de sacolas plásticas: Produto é responsável por maioria das mortes de bois e ovelhas na capital. Fabricantes de plástico podem ser presos por até um ano. BBC: 2013. Disponível em: <http://ultimosegundo.ig.com.br/ciencia/meioambiente/2013-01-03/mauritania-proibe-uso-de-sacolasplasticas.html>. Acesso em: 15 jan 2013.

DEIRO, Bruno. Sacola plástica voltará a ser vendida em São Paulo. A 1. a Vara Cível do Tribunal de Justiça (TJ) de São Paulo aceitou ontem o recurso do Walmart e cassou a liminar que obrigava a distribuição gratuita. Jornal $\mathbf{O}$ Estado de São Paulo: São Paulo, 09 de agosto de 2012. Disponível em: <http://exame.abril.com.br/meio-ambiente-eenergia/noticias/sacola-plastica-voltara-a-ser-vendida-em-sao-paulo>. Acesso em: 06 jan 2013.

GUIMARÃES, Leonardo Durval Duarte; ALBUQUERQUE, Elaine Cristina Barbosa da Silva. Embalagens plásticas num contexto maior. Anais eletrônicos... III SENEPT Seminário Nacional de Educação Profissional e Tecnológica. Belo Horizonte, MG. $2010 . \quad$ Disponível em: <http://www.senept.cefetmg.br/galerias/Anais_2010/Artigos/GT1/EMBALAGENS_PLASTICAS.pdf>. Acesso em: 05 jan 2013.

MEDEIROS, Efraim da Silva; PINTO, Marcelo Ferreira; MACHADO, Flávio Silva. A Substituição de Sacolas Plásticas nos Supermercados com o Apelo Ambiental e seus Impactos na Percepção do Consumidor - Um estudo de caso no Município de Volta Redonda, RJ. Anais eletrônicos... VII SEGeT. Simpósio de Exelencia em Gestão e Tecnologia. Rio de 
Janeiro,

2010.

Disponível

em:

<http://www.aedb.br/seget/artigos10/254_Artigo_Efraim,_Flavio_e_Marcelo_Seget_2010.pdf>. Acesso em: 06 jan 2013.

MINISTÉRIO DO MEIO AMBIENTE. Saco é um Saco. MMA: Brasilia, 2013. Disponível em: <http://www.mma.gov.br/component/k2/item/7658?ltemid=852>. Acesso em: 17 jan 2013.

OLIVEIRA, Luzibênia Leal; LACERDA, Cícero de Sousa; ALVES, Isabel Joselita Barbosa da Rocha; SANTOS, Edilene Dias; OLIVEIRA, Sanuyla de Albuquerque; BATISTA, Tatyane Sales de Araújo. Impactos ambientais causados pelas sacolas plásticas: o caso campina grande - PB. BioFar: Revista de Biologia e Farmácia. V. 7, no 1, 2012. Disponível em: <http://eduep.uepb.edu.br/biofar/v7n1/impactos_ambientais_causados_pelas_sacolas_plasticas.pdf>. Acesso em: 15 jan 2013.

PORTAL EDUCAÇÃO. Sacolas Plástica x Meio Ambiente: Como re(agir)?. Portal Educação: [s.l.], 2012. Disponível em: <http://www.portaleducacao.com.br/biologia/artigos/14622/sacolas-plastica-x-meio-ambiente-como-

reagir\#ixzz2IFMeCQf4>. Acesso em: 07 jan 2013.

PÓVOA NETO, Herminio Henriques; RANGEL, Shayane Azevedo; CORREA SOBRINHA, Memorina Aparecida; DELATORRE, Andréia Boechat; AGUIAR, Cristiane de Jesus; RODRIGUES, Priscila Maria. SACOLAS PLÁSTICAS: CONSUMO INCONSCIENTE. Perspectivas Online: Biológicas e Saúde. V. 1, no 3, 2011. Disponivel em: <http://www.doaj.org/doaj?func=abstract\&id=1082913\&recNo=6\&toc=1\&uiLanguage=en>. Acesso em: 14 jan 2013. QUEIROZ, Guilherme de C.; GARCIA, Eloísa E. C.. Reciclagem de sacolas plásticas de polietileno em termos de inventário de ciclo de vida. Polímeros, São Carlos, v. 20, n. 5, $2010 . \quad$ Disponível em: <http://www.scielo.br/scielo.php?script=sci_arttext\&pid=S0104-14282010000500014\&lng=en\&nrm=iso>. Acesso em: 18 Jan 2013. Doi: http://dx.doi.org/10.1590/S0104-142820110050000033.

RIBEIRO, Paulo Silvino. 0 fim da sacola plástica em nome do meio ambiente: Na luta contra a poluição do meio ambiente, uma das medidas adotadas foi o fim da sacola plástica distribuída por supermercados. Sua substituição já começou em algumas cidades. Brasil Escola: São Paulo, 2013. Disponível em: <http://www.brasilescola.com/sociologia/o-fim-sacola-plastica-nome-meio-ambiente.htm>. Acesso em: 12 jan 2013. SANTANA, Marylin Cipollini. Impacto ambiental causado pelo descarte de embalagens plásticas - gerenciamento e riscos. Monografia apresentada ao curso de tecnologia em produção com ênfase em plástico. 90f, 2009. Centro Tecnológico da Zona Leste. Faculdade de Tecnologia da Zona Leste. São Paulo, 2009. Disponível em: <http://fateczl.edu.br/TCC/2009-1/tcc-121.pdf>. Acesso em: 10 jan 2013.

SILVA, Diogo. Quais são os impactos ambientais das sacolas plásticas? Instituto Ressoar: São Paulo, 2013. Disponível em: <http://www.ressoar.org.br/dicas_reciclagem_sacolas_oxiobiodegradaveis_impactos.asp>. Acesso em: 17 jan 2013.

VILLELA, Josely Nunes; EIGENHEER, Emilio. Mudança comportamental do consumidor a partir de sacolas plásticas: iniciativa em prol da sustentabilidade em comunidade cristã. Produção UFF: Rel. Pesq. v. 11, no 6, 2011. Disponível em: <http://www.producao.uff.br/conteudo/rpep/volume112011/RelPesq_V11_2011_06.pdf>. Acesso em: 13 jan 2013.

ZIEGLER, Maria Fernanda. Por que a sacola de plástico é prejudicial ao meio ambiente: Entenda o problema das sacolas plásticas e quais as alternativas ambientalmente corretas para transportar suas compras. iG: São Paulo, 2010. Disponível em: <http://ultimosegundo.ig.com.br/ciencia/meioambiente/por-que-a-sacola-de-plastico-e-prejudicialao-meio-ambiente/n1237730908104.html>. Acesso em: 09 jan 2013. 